\title{
METODOLOGIA DA PESQUISA EM DIREITO E A GERAÇÃO Z: ESTRATÉGIA DIDÁTICA APLICADA NO CENTRO UNIVERSITÁRIO ALVES FARIA ENTRE
}

2012 E 2018

\section{Luciana Ramos Jordão ${ }^{1}$ Denise Pineli Chaveiro}

RESUMO: O trabalho discute a estratégia didática aplicada pelos professores do Centro Universitário Alves Faria aos alunos de primeiro período do curso de graduação em Direito. Aborda as características da Geração Z, bem como a compreensão da geração que lhe sucederá, a Geração Alfa. Narra o trabalho realizado pelos professores destacando a estratégia utilizada na disciplina de Metodologia da Pesquisa em Direito, bem como o enfoque na interdiciplinaridade como forma de otimizar o processo de aprendizagem. Aborda as ferramentas e metodologias utilizadas como estratégia para promover o ensino interdisciplinar por meio das teorias de Dewey e Freire.

PALAVRAS-CHAVE: Metodologias Ativas; Geração Z; Geração Alfa; Autonomia; Planejamento e Avaliação.

\section{METHODOLOGY OF RESEARCH IN LAW AND GENERATION Z: DIDACTIC STRATEGY APPLIED IN THE UNIVERSITY CENTER ALVES FARIA BETWEEN 2012 AND 2018}

\begin{abstract}
The paper discusses the didactic strategy applied by the teachers of the University Center Alves Faria to the first period students of the law degree course. It addresses the characteristics of Generation Z, as well as the understanding of the generation that will succeed it, the Alpha Generation. It narrates the work done by the teachers highlighting the strategy used in the discipline of Law Research Methodology, as well as the focus on interdiciplinarity as a way to optimize the learning process. It addresses the tools and methodologies used as a strategy to promote interdisciplinary teaching through the theories of Dewey and Freire.
\end{abstract}

KEYWORDS: Active methodologies; Generation Z; Alpha Generation; Autonomy; Planning and Evaluation.

\footnotetext{
${ }^{1}$ Doutoranda do Programa de Pós-Graduação em Agronegócio - UFG. Mestre em Direito Agrário - UFG. Graduada em Direito - UFG. Advogada e Professora do Centro Universitário Alves Faria - UNIALFA.

${ }^{2}$ Advogada. Professora de Direito Civil e Processo Civil no Centro Universitário de Goiás UNI-Anhanguera e Centro Universitário Alves Faria - UNIALFA. Especialista em Direito Processual pela Unisul. Email: denisepineli@gmail.com.
} 


\section{INTRODUÇÃO}

Este trabalho apresenta estratégia didática desenvolvida pelos autores entre os anos de 2012 e 2018 com alunos do primeiro período da disciplina de Metodologia da Pesquisa em Direito, da graduação em Direito no Centro Universitário Alves Faria (UNIALFA), localizado em Goiânia, a fim de promover abordagem interdisciplinar e por meio de processos simulados.

Até 2011, a disciplina de Metodologia Científica era ministrada por docentes vincula dos aos cursos de Pedagogia com formações diversas. Ao longo das oitenta horas de curso, discutia-se a construção do conhecimento, os tipos de conhecimento e suas variadas espécies, as normas para elaboração de trabalhos acadêmicos, entre outros pontos tradicionalmente abordados na disciplina.

Verificou-se, no entanto, que a despeito de reconhecerem a importância do conteúdo trabalhado pelos docentes, os alunos não percebiam conexão entre os tópicos abordados e os temas que eles imaginavam que seriam colocados sob seus cuidados ao longo da graduação. Como decorrência da falta de interesse e motivação pela temática da disciplina, percebia-se significativo índice de faltas, que se somavam à crença de impossibilidade de reprovação em disciplinas externas ao eixo profissionalizante.

Considerando estes aspectos, a Coordenação e a equipe de professores resolveram empreender esforços no sentido de ampliar as discussões realizadas pelos discentes por meio da integração dos conteúdos da grade do primeiro período. Para tanto, utilizou-se a disciplina de Metodologia Científica, que passou a ser denominada Metodologia da Pesquisa em Direito.

Além de modificar a forma de avaliação e a ementa da disciplina, também se passou a utilizar o processo simulado a fim de estimular o interesse dos discentes pelamatéria , e permitir a abordagem interdisciplinar, o trabalho em equipe, o desenvolvimento de habilidades de pesquisa e a autoestima dos alunos.

O objetivo deste artigo consiste em discutir as estratégias didáticas utilizadas no curso de Direito a partir do relato da experiência dos professores do UNIALFA, tendo em vista os desafios de se lecionar no século XXI. Para tanto, divide-se o trabalho em três seções.

A primeira delas aborda a necessidade premente de conhecer as características da Geração Z, bem como a compreensão que ela está deixado lugar para uma nova, denominada Geração Alfa. 
A segunda sessão narra o trabalho realizado pelos professores do UNIALFA destacando a estratégia utilizada na disciplina de Metodologia da Pesquisa em Direito, bem como o enfoque na interdiciplinaridade como forma de otimizar o processo de aprendizagem.

Em seguida, a última sessão aborda as ferramentas e metodologias utilizadas como estratégia para promover o ensino da disciplina aos alunos de primeiro período.

Acredita-se que a educação, enquanto fenômeno inevitável da vida deriva do desenrolar das experiências refletidas para construção do ser humano, desse ensaio decorre uma ampliação da inteligência necessária para dirigir de forma mais segura as futuras percepções. Portanto, o fim da educação é a melhora na qualidade de vida dos indivíduos (TEIXEIRA, 2010)

Para promover o desenvolvimento do ser à partir de um processo consciente é necessário ao estudante experimentar e ao mesmo tempo distanciar-se da realidade para fazêla presente e compreendê-la. À partir desta percepção responderá aos estímulos de forma diferenciada em razão da consciência, com a possibilidade de enfrentar as futuras vivências objetivando-as, para transformá-las em desafios, projetando de forma intencional para além dos limites propostos (FREIRE, 1987).

Nota-se, por tudo isso, que é possível desenvolver metodologias ativas de ensino que, de fato, permitam aos alunos desenvolverem suas habilidades e sua independência por meio da pesquisa científica e da integração do quadro docente no planejamento pedagógico.

\section{INTERDISCIPLINARIDADE E DIREITO: A URGÊNCIA DE GERAÇÕES ANSIOSAS POR RESPOSTAS}

A chegada à universidade dos jovens nascidos na década de 1990, que não conheceram (ou não se recordam) da vida anterior à existência do Google e do telefone celular (ou melhor, do smartfone), apresenta novos desafios aos docentes. Salas cheias de alunos munidos de equipamentos que proveem toda sorte de informação requerem novas formas de canalização do foco para que seja possível realizar uma atividade por maior período de tempo (QUINTANILHA, 2017).

A compreensão acerca da época em que se desenvolve cada geração constitui aspecto fundamental quando se deseja refletir a respeito de seus comportamentos e influências. “Os processos formativos, os eventos significativos, e o vir a ser de cada geração, dentro da

Rev. de Pesquisa e Educação Jurídica | e-ISSN: 2525-9636 | Porto Alegre | v. 4 | n. 2 | p. 104 - 120 | Jul/Dez. 2018 
dualidade fim ou causa, que concebem historicamente, se evidencia no cenário que as gerações contemporâneas configuram na sociedade moderna" (INDALÉCIO; RIBEIRO, 2017, p. 139).

A Geração Z demanda que seus professores criem atmosfera que lhes despertem o interesse e a motivação. O professor que atua como moderador ou provocador de atividades das quais os alunos possam participar, estabelecendo vínculo que alcance não apenas as dimensões intelectuais, mas também afetivas, consegue promover aprendizagem mais sólida. Mas, para que isto ocorra, o modelo de aulas incessantemente expositivas deve ceder lugar a propostas que aproximem o aluno da instituição, mantendo sua motivação e participação e realizando avaliações individualizadas que se vinculem à urgência de respostas que demanda a Geração Z (QUINTANILHA, 2017).

Tratam-se de pessoas que não concebem um mundo em que não haja acesso à Internet. Os jovens nascidos nos anos 1990 se expressam por meio do compartilhamento de suas rotinas, fotos e sentimentos e buscam constante autoafirmação. A eles importa a obtenção de informações e o local em que os dados são disponibilizados, que, se considerados válidos serão replicados e contribuirão para a criação de uma inteligência coletiva (INDALÉCIO; RIBEIRO, 2017).

Portanto, em lugar de bloquear o acesso às redes sociais e o uso dos smartfones durante as aulas, maior utilidade há em fazer uso desses instrumentos para prover o maior número de fontes confiáveis de pesquisa. O Facebook e o YouTube estão fartos de dados e portas de acesso a conteúdo de proveniente de centros de excelência no Brasil e no exterior que devem integrar o cotidiano dos professores e alunos. A apresentação de caminhos que possam ser trilhados com essas ferramentas pelos alunos constitui forma de promoção de autonomia para os alunos que, em lugar de se afastar do professor, julgando-o ultrapassado e desconectado da realidade contemporânea, passam a tratá-lo como referência de confiabilidade (QUINTANILHA, 2017).

[...] a prática da construção de conhecimento interdisciplinar exige do pesquisador uma postura diferenciada daquela que tradicionalmente se adota. A necessidade de desenvolver novos paradigmas e métodos, essenciais para assegurar o rigor e a confiabilidade do conhecimento gerado, exigirá a renúncia de paradigmas e métodos já consolidados nos diversos campos disciplinares, bem como a constituição de equipes multidisciplinares (HOFF et al, 2007, p. 44).

O desenvolvimento de novas práticas por meio de construção de conhecimento interdisciplinar, já proposto por Dewey, ganha ainda mais destaque com a entrada dos jovens 
da Geração Z no ensino superior. Contudo, constituirá realidade inafastável no momento em que a Geração Alfa, que remete aos nascidos a partir de 2010, chegarem às Universidades.

De acordo com o entendimento de Dewey(2015), o aprendizado não resulta da mera apresentação de conceitos perceptíveis e apreensíveis por meio dos sentidos. De fato, as características que imprimem significados aos conceitos e lhes conferem utilidade são responsáveis pela identificação pelo aprendiz do conhecimento, que não pode ser confundido com mera resposta a um estímulo físico. Assim, o treinamento para repetição de algo que não tenha significado para quem aprende pode resultar em alguma ação, mas não em educação, porque a resposta é cega e inconsciente.

\footnotetext{
A escola classifica ainda cada uma das matérias. Os fatos são retirados de seu lugar original e reorganizados em vista de algum princípio geral. Ora, a experiência infantil nada tem de ver com tais classificações; as coisas não chegam ao seu espírito sob esse aspecto. Somente os laços vitais de afeição, e os de sua própria ativi- dade prendem e unem a variedade de suas experiências sociais.

A mentalidade adulta está familiarizada, todavia, com a noção de ordem lógica dos fatos, que não reconhece - não pode reco- nhecer - o espantoso trabalho de separação, de abstração e mani- pulação, que tem de sofrer os fatos de experiência direta para que possam aparecer como uma "matéria" ou um ramo de saber (DEWEY, 2010, p. 71).
}

A Geração Alfa, tendo em vista as óbvias limitações da pesquisa científica, não possui características seguramente identificáveis. As pesquisas a respeito das perspectivas de comportamento desta geração consideram as características da educação, acesso à tecnologia e convivência familiar e social da terceira geração de nativos digitais (TOOTELL; FREEMAN, M.; FREEMAN, A., 2014). Acredita-se que a Geração Alfa será composta por pessoas que tiveram mais acesso a recursos materiais porque seus pais começaram suas famílias aos 30 anos, quando já dispunham de alguma estabilidade financeira. A geração Alfa tende a utilizar a tecnologia com ainda mais fluidez do que sua antecedente, mas também padecerá com a solidão decorrente da criação que lhes provê elevado senso de auto importância (INDALÉCIO; RIBEIRO, 2017).

A Geração Alfa já vai à escola e está menos preparada para realizar raciocínio matemático e de linguagens, mas podem manter o foco em várias atividades distintas concomitantemente, são capazes de formular hipóteses e definir estratégias de modo bastante ágil e conseguem interpretar facilmente imagens tridimensionais (INDALÉCIO; RIBEIRO, 2017). Um mundo de repetição de estímulos para fixação de um hábito (DEWEY, 2015) que não inclua a tecnologia, por exemplo, não faz qualquer sentido para as crianças da Geração 
Alfa. Em breve, estas crianças chegarão às Universidades e o ensino disciplinar, no ensino fundamental, já não é bastante para atender às suas expectativas, desenvolver suas habilidades e vencer suas dificuldades.

São sensíveis as consequências que a superação da pauta disciplinar apresenta às equipes de professores e a todo o sistema de educação. A construção de ambiente voltado à interdisciplinaridade, que estimule o trabalho em equipe e a realização de linguagem científica e atrelada às necessidades e interesses dos alunos requer ambiente e currículos que prestigiem este tipo de saber em lugar de servir como entrave a seu estabelecimento (HOFF et al, 2007).

Aos professores formados sob o signo da disciplinaridade cabe o desafio de abandonar o conforto e a estabilidade gerada pela generalização simbólica, que constitui o arcabouço teórico sob o qual se ampara o saber, bem como seus modelos e exemplos. "O modelo representa o método, a forma de abordar o objeto que é típico de cada disciplina. Os exemplos são os objetos aos quais se aplica o modelo, cujos resultados são traduzidos pela simbologia própria desta disciplina” (HOFF et al, 2007, p. 45). Por vezes, estes fatores não mais expressam as respostas para os questionamentos que envolvem o cotidiano dos alunos da Geração Z. O senso de defitividade e estabilidade das disciplinas é insuficiente para compreender um mundo em que tudo e todos se conectam. Da necessidade de utilização de diversas linguagens, métodos, objetivos e maneiras de se perceber esses objetivos, estabelecemse a multidisciplinaridade e a interdisciplinaridade (HOFF et al, 2007).

A multidisciplinaridade se realiza por meio da avaliação de um objeto a partir de múltiplas perspectivas que reflitam sua complexidade sem, contudo, provocar alterações nos conteúdos das disciplinas envolvidas. Logo, a prática multidisciplinar faz uso dos conhecimentos provenientes de diversas fontes, mas não implica na produção, construção ou alteração do conhecimento previamente estabelecido. As disciplinas continuam existindo isoladamente, não havendo relação de interdependência entre elas (HOFF et al, 2007).

Em abordagens multidisciplinares, a equipe de docentes apresenta a perspectiva individual de suas disciplinas de modo sequencial. Fica a cargo dos alunos avaliar as diferenças entre as considerações tecidas na análise de cada conteúdo e realizar a integração que lhes deseja pertinente. Os professores trabalham para realizar sínteses das partes de cada disciplina a fim de prover visão mais ampla de a respeito de um problema (KLEIN; NEWELL, 1997).

Quando o processo multidisciplinar passa a ser estabelecido de modo que se observe relação de necessária dependência entre os conhecimentos, é possível considerar a 
etapa de interdisciplinaridade. Havendo interdisciplinaridade, deixa de ser suficiente a mera cooperação entre as disciplinas visando retirar delas o conteúdo que possa ser aproveitado no atendimento imediato de um objetivo comum. A interdisciplinaridade implica a obtenção conjunta de soluções que só podem ser alcançadas por meio da cooperação entre as disciplinas que passarão a existir de modo indissociável entre si (HOFF et al, 2007). "Essa combinação de disciplinas adiciona valor ao processo, sendo possível perceber que o resultado obtido pelo estudo conjunto é mais interessante do que a soma das contribuições individuais das partes" (HOFF et al, 2007, p. 46).

The more activity is restricted to a few definite lines-as it is when there are rigid class lines preventing adequate interplay of experiences-the more action tends to become routine on the part of the class at a disadvantage, and capricious, aimless, and explosive on the part of the class having the materially fortunate position (DEWEY, 2015, p. 47).

A diversidade de estímulos e a novidade impulsionam a curiosidade. $\mathrm{O}$ isolamento dos conhecimentos prejudica a eficiência na compreensão da completude dos problemas e a motivação humana na busca por soluções. Para Dewey(2015), a separação e isolamento de fatores que compõem um problema são responsáveis pela institucionalização formal da vida e a falta de compreensão acerca de um problema. Paradoxalmente, o isolamento resulta de resposta a um problema em que, em lugar de reorganização para ampliação das relações e alcance de progresso, opta-se pela proteção contra fatores externos. "It marks nations in their isolation from one another; families which seclude their domestic concerns as if they had no connection with a larger life; schools when separated from the interest of home and community; the divisions of rich and poor; learned and unlearned" (DEWEY, 2015, p. 48).

No caso do curso de Direito, como em outras áreas, cabe trabalhar para construir espaço de democracia que atribua responsabilidades aos discentes, que atribua responsabilidades aos discentes tornando-os protagonista no processo de aprendizagem, ao mesmo tempo em que se proporciona espaço em que haja liberdade para discussão e respeito ao conhecimento prévio do qual dispõem os alunos. O professor deixa o papel de transmissor para tomar uma atitude de mediador do conhecimento, fomentando atitudes participativas através de metodologias ativas.

A interdisciplinaridade, no estudo do Direito só é possível se se apresentar os temas e problemas humanos utilizando o conhecimento jurídico como instrumento de resolução destas 
questões. A teoria dissociada da prática perde o sentido e impede que o estudante aprenda. Wesbrook(2010) destaca a dificuldade que a Pedagogia de Dewey apresenta ao professor a quem cabe inserir os temas estudados na experiência em lugar de impor ao estudante algo que foi resultado das situações vividas por outras pessoas ao longo da história.

$\mathrm{Na}$ interdiciplinaridade, as disciplinas se unem em um projeto comum, previamente planejado para sua intersecção, todas as áreas trocam conhecimentos e se enriquecem, proporcionando um novo saber, menos fragmentado, mais dinâmico e colaborativo, o que acarretará a ressignificação da experiência de aprendizado.

\section{A CONSTRUÇÃO DA INTERDISCIPLINARIDADE NA GRADUAÇÃO EM DIREITO}

O ser humano vive de experiências que podem ser traduzidas pelas suas ações e reações em um aspecto macro, que ultrapassam as escolhas feitas com base no aspecto puramente biológico, estas decisões são permeadas pela reflexão, pelo conhecimento e pelo processo de aprendizagem. A experiência pode ser traduzida pela interação entre os elementos, produzindo neles modificações. O mecanismo dual de perceber o racionalismo e o intelectualismo produz uma experiência fulgaz e solitária, contra uma realidade exterior em movimento (TEIXEIRA, 2010).

Para Teixeira (2010) a análise da experiência demanda o conhecimento de dois fatores - agente e situação, onde cada tem sua carga de influência sobre o outro, com simultânea capacidade de reação entre eles, destacando que a maior significação deste processo acontece quando isso é feito de forma consciente, o que dá significado pelo conhecimento, que nos torna aptos a conduzi-la para solução de outras questões ou mesmo para melhor autodeterminar-se em novas experiências.

Para melhor vivenciar suas experiências o estudante de gradução desta Geração Z precisa experimentar estes conteúdos de forma interdisciplinar.

A realização da interdisciplinaridade enquanto mudança institucional parte, conforme Klein e Newell(1997), de dois princípios: reconhecer a realidade efetivamente presente no sistema em lugar de impor modelos previamente concebidos e compreender que a interdisciplinaridade não consiste em concordância conceitual, política ou prática.

Pelo primeiro princípio se conclui que é preciso avaliar o sistema em curso antes de realizar mudanças que remetam a pacotes de soluções que nem sempre guardam relação com 
as mudanças necessárias. Mesmo porque, ao analisar a complexa estrutura de currículos, podese identificar a presença de maior nível de atividades interdisciplinares do que se pudesse inicialmente imaginar (KLEIN; NEWELL, 1997).

O segundo princípio destaca que a interdisciplinaridade decorre da confluência entre visões disciplinares, capacitação profissional e filosofia educacional. Neste ponto, cabe à instituição de ensino avaliar sua própria natureza, as possibilidades de interação entre os docentes, entre a equipe de professores e a administração, entre outros aspectos como interesses dos professores e estilo de aprendizagem dos alunos (KLEIN; NEWELL, 1997).

Nesse ponto, importa considerar a relevância da participação democrática dos professores e da administração na elaboração do currículo e do curso a fim de que se construa noção de completude que naturalmente resulte de ambiente democrático (DEWEY, 2015). Afinal, é insustentável crer que o conhecimento e a interdisciplinaridade possam ocorrer quando há imposição de prática ou comportamento.

Ao elaborar um programa que se pretenda interdisciplinar, cabe aos professores conjuntamente considerar a escolha de um tópico em torno do qual se estruturem as disciplinas. Klein e Newell(1997) entendem que a escolha de um tema, problema, questão, ideia, pessoa, povo período histórico ou cultural é necessária para integrar a organização das disciplinas. A partir disto, cabe avaliar o modo pelo qual a abordagem interdisciplinar se insere no programa da instituição, discutindo-se sua inserção na sequência do curso e como o processo será dirigido. O objetivo reside em equilibrar a ampla gama de conhecimentos com a qualidade e profundidade da abordagem e a possibilidade de realização de síntese que integre todos os aspectos trabalhados (KLEIN; NEWELL, 1997).

\section{ESTRATÉGIA DIDÁTICA PARA ENSINO DE METODOLOGIA DE PESQUISA EM DIREITO NO PRIMEIRO PERÍODO DE GRADUAÇÃO}

A partir de 2012, propomos uma alteração na forma de avaliação da disciplina, antes dividida em três ciclos com uma recuperação, onde o primeiro e segundo ciclos eram compostos por avaliação formal, através de prova, e avaliação através de trabalhos, o terceiro ciclo, composto por uma prova para aqueles que não atingissem média de 8,0 pontos nos dois primeiros.

Não alterando a metodologia dos ciclos, foi proposta uma alteração na forma de composição das avaliações do primeiro e segundo ciclos.

Rev. de Pesquisa e Educação Jurídica | e-ISSN: 2525-9636 | Porto Alegre | v. 4 | n. 2 | p. 104 - 120 | Jul/Dez. 2018 
Inicia-se pela apresentação do conteúdo disposto na ementa da disciplina, trabalhando conceitos formais os quais foram exigidos nas provas formais. Neste primeiro ciclo começa o processo de sensibilização e abordagem dos aspectos positivo da interdisciplinaridade e do trabalho em equipe para melhor desenvolvimento do conteúdo.

No segundo ciclo a segunda avaliação formal da disciplina de Metodologia de Pesquisa em Direito foi substituída pela elaboração de dois trabalhos realizados em grupos que continham entre três e seis alunos.

A escolha dos integrantes dos grupos foram feitas pelos próprios discentes, conforme suas afinidades, destaca-se neste ponto a importância do trabalho em equipe tanto para o aprendizado como para a vida profissional.

O primeiro dos trabalhos consiste em elaborar um breve artigo científico acerca de tema escolhido pelos próprios alunos. Este tema deve permear questões pertinentes ao universo do curso de Direito, de forma interdisciplinar. Seguindo as lições de Dewey (2010; 2015), Freire (2000), Klein e Newell(1997), etre tantos outros estudiosos, busca-se definir um eixo de interesse comum que possa se aproveitar dos conhecimentos dos alunos e despertar seus interesses de modo a incentivar o comportamento crítico e autônomo.

\footnotetext{
Primeiro, um princípio, de ordem intelectual, tem de ser definido e adotado; depois, os fatos têm de ser interpretados em relação a esse princípio - não tais quais eles são - para, afinal, reunidos, em volta desse centro novo, inteiramente ideal e abstrato, construírem um departamento do conhecimento humano.

Tudo isso supõe um interesse intelectual desenvolvido e espe- cializado. Envolve capacidade de analisar os fatos imparcial e ob- jetivamente, isto é, sem referência ao seu lugar e sentido, em nossa própria experiência. Exige capacidade de síntese. Significa, enfim, hábitos intelectuais amadurecidos, e a posse de uma especializada investigação científica ( DEWEY, 2010, p. 71).
}

O docente encarregado da disciplina auxilia os discentes na formulação do problema, bem como os auxilia com sugestão das diversas formas de pesquisa e na construção do texto, que deve se adequar ao eixo temático estabelecido pela equipe de professores a cada semestre.

A fim de integrar os conhecimentos discutidos nas disciplinas de Introdução ao Estudo de Direito, Antropologia e Direito e Teoria Geral do Direito Civil I, são trabalhados os direitos da personalidade dentro da perspectiva dos direitos humanos.

Assim, os alunos debatem temas como o direito à vida, à igualdade, à privacidade, à dignidade da pessoa humana, à intimidade e honra, produzindo trabalhos que versam dos mais 
variados assuntos, que vão desde o infanticídio indígena à elaboração de políticas públicas de igualdade de gênero e à reforma agrária. Busca-se inserir o eixo temático nos assuntos que sejam de interesse dos alunos a fim de lhes permitir aproveitar o desejo natural de conhecer o Direito.

Seguindo os ensinamentos de Dewey, parte-se da premissa de que o “[...] pluralismo, por outro lado, abre espaço para a contingência, a liberdade, a novidade e fornece liberdade de ação completa para o método empíico, que pode ser indefinidamente estendido. Aceita a unidade onde a encontra, mas não procura forçar a vasta diversidade dos eventos e coisas a um molde racional único" (DEWEY, 2007, p. 232).

Para a confecção do trabalho, são realizadas aulas em que se chama atenção para as regras necessárias à elaboração de citações, referências e formatação. O plágio também é abordado nesta etapa, quando se apresentam aos discentes formas de pesquisar as bases de dados do UNIALFA e os bancos abertos de artigos acadêmicos.

Os alunos produzem artigos curtos utilizando formato semelhante ao adotado pelo Conselho Nacional de Pesquisa e Pós-graduação em Direito (CONPEDI). Assim, é possível discutir perspectivas atreladas à carreira acadêmica e apresentar as possibilidades de pesquisa científica em Direito. No primeiro período, integra a grade a disciplina de Português Instrumental Forense, à qual se confere destaque por se tratar de instrumento de trabalho fundamental daquele que busca empreender pesquisa acadêmica ou trilhar as carreiras jurídicas.

Notou-se, neste ponto, um acréscimo de auto estima nos grupos decorrente dos trabalhos realizados, antes incipientes passam a sentir-se confiantes a engajados no processo de aprendizagem, abandonando a postura de depositário para fazer frente a uma educação proativa.

É possível observar que essa alteração permitiu aos alunos uma autonomia de busca pelo conhecimento próprio de seu fazer profissional. Paulo Freire(2000) salienta que a educação é um campo político atuante e que deve capacitar o aluno a promover uma leitura de mundo. $\mathrm{O}$ desafio instigante de possibilitar o aluno de primeiro período a mergulhar no mundo da pesquisa, buscando conhecimentos em sua própria área de formação, em temas que o interessem, tem sido responsável por uma melhoria significativa e produtiva no que tange aos resultados da disciplina.

Visando fomentar a pesquisa, a partir destes trabalhos, os alunos produzem pôsteres que são apresentados no evento de iniciação científica realizado anualmente pelo UNIALFA. 
Os pôsteres são avaliados pelos docentes e compõem os anais do evento. Os alunos recebem certificados de apresentação dos trabalhos.

O segundo trabalho consiste na elaboração de peças processuais a partir de casos hipotéticos nos quais os alunos elaboram uma petição inicial, uma peça de defesa e uma sentença de processo cível.

A redação das peças é feita em formato aproximado àquele exigido pela banca responsável pela aplicação dos Exames de Ordem. Por óbvio, não é possível cobrar a atenção a todas as determinações constantes no aparato legal adjetivo, mas questões básicas tais como qualificação das partes, estruturação de pedidos, causa de pedir remota e próxima são introduzidas ao longo das aulas.

Percebe-se que o aluno neste ponto, mesmo com conhecimentos incipientes sobre as matérias processuais tornam-se protagonistas do processo de aprendizagem, mais encorajados para a vida acadêmica e menos propensos à evasão, tão própria dos primeiros semestres de curso.

Neste processo também é utilizada a Plataforma Moodle com acesso, através de rede mundial de internet como ferramenta de comunição e disponibilização de materiais, além de fóruns de debates onde os alunos podem colocar suas dificuldades. Também se utiliza como forma de comunicação as redes sociais e o aplicativo WhatsApp. A tecnologia é vista como elemento facilitador da integração entre os conhecimentos dos professores e alunos, colocandoos no mesmo espaço de diálogo a fim de facilitar a descoberta da realidade a que ambos pertencem, conforme sugere Dewey(2010).

Os prazos assinalados para entrega dos trabalhos constam em Edital divulgado na Plataforma Moodle, bem como materiais que podem ser utilizados para a fundamentação das peças e padrões de formatação aceitos pelo Núcleo de Prática Jurídica do UNIALFA. Os alunos aprendem a importância de tratar com responsabilidade e diligência de suas obrigações além das consequências que podem advir do descumprimento de um prazo legal.

Os nascidos na Era da Informação já usufruem de um volume gigantesco de conteúdos informacionais disponibilizados em rede, com tendência de crescimento garantido e, com acesso cada vez mais facilitado. Distinto dos recursos tradicionais de acesso a informação, que fizeram parte da formação dos Imigrantes Digitais, a virtualização do conhecimento promove a formatação de um novo paradigma social e educacional, que não pode mais ser ignorado e, que definitivamente reflete desafios à sociedade contemporânea (INDALÉCIO; RIBEIRO, 2017, p. 143-144). 
Ainda nesta etapa, os discentes produzem a documentação que será juntada à inicial, como procuração, documentos pessoais, comprovantes, entre outros, e simulam o protocolo e a autuação do feito. Na oportunidade, são feitos esclarecimentos a respeito da movimentação do processo, do papel do advogado, de técnicas de planejamento para redação do texto e pesquisa em doutrinas e informes jurisprudenciais. Além da forma de apresentar a eles os meios eletrônicos onde tramitam os processos judiciais, bem como as ferramentas disponíveis nos sítios dos tribunais para pesquisas sobre os temas.

Geralmente, os alunos se sentem bastante motivados a participar das atividades e expandem os debates travados durante as aulas de Metodologia a outros momentos. A equipe de docentes costuma relatar a realização de questionamentos a respeito do andamento processual, possibilidades de conciliação e resolução extrajudicial e formas de produção de provas, entre outros temas.

Protocolada a inicial, autuado e distribuído o feito, dado o despacho inicial, dispensa-se a audiência de conciliação e se abre prazo para elaboração da defesa. Para isso, busca-se revezar os processos simulados para que os discentes tenham contato com outros casos, se possível, realizados em outras turmas de primeiro período.

Nesta fase, os alunos são incentivados a pesquisar de modo mais independente do material, utilizando os canais de pesquisa que também serviram para a elaboração dos artigos científicos. Encerrado o prazo para apresentação de defesa, os processos simulados são distribuídos às equipes que se ocupação da prolação de sentença.

Entende-se que a presença de vícios processuais - obviamente cometidos pelos alunos iniciantes - não deve constituir critério a ser cobrado dos alunos responsáveis por esta etapa do trabalho. Geralmente, a maior parte dos processos se encerra com a resolução do mérito. Todavia, houve casos em que os alunos puderam identificar a impossibilidade de solução de mérito. Mesmo porque, ao elaborar a defesa, outros colegas conseguem identificar aspectos processuais que integram a pesquisa por eles realizada.

Esta forma de avaliação tem como objetivo construir ambiente adequado à criação dos hábitos de discussão inteligente e vinculado à realidade dos alunos de modo que os estudantes aprendam a cooperar entre si, respeitando os espaços de debate e se auxiliando na resolução dos problemas propostos. Infelizmente, em ambiente político de extrema polarização, em que os temas são fundamentados em paixões e não por ideias, acaba-se passando pelo mesmo "aborrecimento" relatado por Westbrook, que notou que "[...] a maioria das escolas não 
foi concebida para transformar a sociedade, mas para reproduzi-la". A dificuldade é ampliada porque os alunos de primeiro período carregam ainda toda a cultura das instituições que os abrigaram ao longo do ensino fundamental e médio.

De fato, nem sempre é possível manter a boa convivência entre os estudantes. Eventualmente, criam-se inimizades entre os alunos, grupos são desfeitos e refeitos. Mas, pelo que se pode experimentar, o êxito decorrente desta estratégia tem sido mais comum do que o desacerto.

A ideia é transformar o processo de aprendizagem em uma experiência significativa e interdisciplinar.

A finalidade é atentar para uma experiência educativa e inteligente, compreendida como aquela onde o pensamento é destacado a partir das percepções reflexivas da realidade, que ultrapassam barreiras para enriquecer o espírito, dando à vida um significado maior e mais profundo. Esta é a essência da educação, alargar horizontes, fazer do conhecimento uma ferramenta para o crescimento espiritual, enquanto seres humanos, transformando a realidade em algo melhor (TEIXEIRA, 2010).

\section{CONSIDERAÇÕES FINAIS}

A guisa de conclusões convém ressaltar que Dewey(2010) vê a educação como um processo no qual se reconstrói e se reorganiza a experiência. E, a partir deste processo, cabe perceber o sentido dos conceitos e fatos com profundidade suficiente a habilitar o aluno e o professor a serem senhores de seus próprios destinos e ações.

Segundo Teixeira (2010) “a educação é fenômeno direto da vida, tão inelutável como a própria vida. A contínua reorganização e reconstrução da experiência pela reflexão" o que se constitui como marco característico humano.

A educação é uma necessidade da vida social da vida, e se demonstra em seus mais simples aspectos, além de permitir subjulgar e controlar, em proveito da perpetuação da espécie, as energias que, de outro modo, destruiriam os seres humanos. Sem essa transmissão do conhecimento entre as gerações os grupamentos sociais, depressa retornariam a sua condição primitiva (TEIXEIRA, 2010).

Com foco nesta visão a readequação do processo de aprendizagem da disciplina Metodologia de Pesquisa em Direito nos proporcionou uma rica experiência para a percepção da necessidade de drásticas mudanças no processo de aprendizagem dos discentes advindos da

Rev. de Pesquisa e Educação Jurídica | e-ISSN: 2525-9636 | Porto Alegre | v. 4 | n. 2 | p. 104 - 120 | Jul/Dez. 2018 
geração $\mathrm{Z}$ que se mostram totalmente conectados à internet, de onde retira sua maior fonte de experiências.

A partir desta nova visão, e da readequação de nossos Projetos Pedagógicos de Curso pode-se promover um processo de aprendizado com conteúdos interativos e interdisciplinares com o uso de metodologias ativas, proporcionando aos discentes uma experiência mais adequada ao seu perfil e com isso ampliando seu interesse e a transformação disso em conhecimento.

O esforço dos profissionais envolvidos no processo educacional para a produção e ampliação dos horizontes do conhecimento é medida que se impõe, a partir da percepção de que a aprendizagem é ativa e significada a partir da experiência, em que se avance em espiral, desde o conhecimento mais elementar até patamares mais complexos, o que demanda reconhecer que a atual geração que está nos bancos universitários aprendem segundo suas habilidades e competências, que é diferentes das habilidades e competências que foram oferecidas aos docentes, requisitando destes uma atitude proativa frente à mudança de paradigma.

O uso de ferramentas com tecnologia em rede e móvel aliada às competências digitais são imprescindíveis para atingirmos uma educação capaz de produzir de fato conhecimento e transformação para melhor o meio em que se vive.

A universidade não pode se distanciar do estudante, que é, em primeira análise, o foco e a sua razão de existir, e como também constitui sua finalidade a produção do conhecimento deve permitir maior interação entre esses atores, implantando o compartilhamento em tempo real de informações pela internet e utilização de aplicativos e redes sociais para servir como meio de aproximar o docente do discente e não ser a causa do seu distanciamento.

Aliar metodologias ativas com tecnologia digital móvel é uma estratégia fundamental para atingir o discente, e esta inovação pedagógica pode alargar significativamente as possibilidades de pesquisa, tutoriais, comunicação e compartilhamento de informações, publicação de conteúdos, multiplicando significativamente os espaços para produção do conhecimento.

O ser humano participa do caráter educativo de suas experiências durante toda sua vida, diferenciando-se efetivamente pelo grau, isso porque, na infância muito pouco há acumulado, o que acarreta um aproveitamento ampliado, enquanto que, na velhice há uma 
menor plasticidade, e consequentemente uma maior dificuldade para o aproveitamento, mesmo assim, o processo educacional como um fenômeno decorrente da própria vida resultado das experiências transmitidas às novas gerações como conquistas de seu processo civilizatório (TEIXEIRA, 2010)

Dentro desta ótica as experiências vividas com os alunos do primeiro período do UNIALFA, dentro da disciplina Metodologia de Pesquisa em Direito, foram de grande significado positivo, a partir do momento em que se passa a ampliar as formas de comunicação do conteúdo, utilizando meios eletrônicos, plataforma Moodle e redes sociais, consegue-se tirar o aluno da posição passiva de depositário do conhecimento para envolve-los como protagonistas deste processo.

Percebeu-se que a utilização de ferramentas de metodologias ativas ampliou consideravelmente o envolvimento do aluno com a sua formação acadêmica, bem como ampliou seu interesse e reduziu a evasão nos primeiros períodos do curso.

Esse hiato entre a formação acadêmica dos professores e a geração Z, que muitas vezes têm muito mais domínio e fluidez na utilização de nova ferramentas interativas e redes sociais, associado a um sentimento e necessidade de autoafirmação, demanda um professor cada vez mais consciente de seu papel de mediador e não como detentor do conhecimento.

\section{REFERÊNCIAS}

DEWEY, John. Democracy and education. [S.1.], 2015. Disponível em: <https://www.gutenberg.org/files/852/852-h/852-h.htm>. Acesso em: 2 set. 2018.

O desenvolvimento do pragmatismo americano. Scieti e studia. São Paulo, v. 5, n. 2 , p. 227-243, 2007.

Vida e educação. In: WESTBROOK, Robert; TEIXEIRA, Anísio; ROMÃO, José Eustáquio; RODRIGUES, Verone Lane (org.). John Dewey. Recife: Fundação Joaquim Nabuco, Editora Massangana, 2010.

FREIRE, Paulo. Pedagogia da autonomia: saberes necessários à prática educativa. 50. ed. Rio de Janeiro: Paz e Terra, 2000.

Pedagogia do Oprimido. 17. a ed. Rio de Janeiro: Paz e Terra, 1987.

HOFF, Debora Nayar et al. Os desafios da pesquisa e ensino interdisciplinares. Revista Brasileira de Pós-Graduação, v. 4, n. 7, 2007.

INDALÉCIO, Anderson Bençal; RIBEIRO, Maria da Graça Martins. Gerações Ze Alfa: os novos desafios para a educação contemporânea. Revista UNIFEV: Ciência \& Tecnologia, v. 2, p. 137-148, 2017.

KLEIN, Julie Thompson; NEWELL, William. Advancing interdisciplinary studies. In: 
Handbook of the undergraduate curriculum: A comprehensive guide to purposes, structures, practices, and change, p. 393-415, 1997.

QUINTANILHA, Luiz Fernando. Inovação Pedagógica Universitária mediada pelo Facebook e YouTube: uma experiência de ensino-aprendizagem direcionado à geração-Z. Educar em Revista, v. 33, n. 65, p. 249-263, 2017.

TEIXEIRA, Anísio. A pedagogia de Dewey: esboço da teoria de educação de John Dewey. In: WESTBROOK, Robert; TEIXEIRA, Anísio; ROMÃO, José Eustáquio; RODRIGUES, Verone Lane (org.). John Dewey. Recife: Fundação Joaquim Nabuco, Editora Massangana, 2010.

TOOTELL, Holly; FREEMAN, Mark; FREEMAN, Alison. Generation Alpha at the intersection of technology, play and motivation. In: HAWAII INTERNATIONAL CONFERENCE ON SYSTEM SCIENCE, 47., 2014, [S. 1.]. Proceedings... . [S. 1.]: IEEE, 2014. p. 82-90.

WESTBROOK, Robert. John Dewey: 1859-1952. In: WESTBROOK, Robert; TEIXEIRA, Anísio; ROMÃO, José Eustáquio; RODRIGUES, Verone Lane (org.). John Dewey. Recife: Fundação Joaquim Nabuco, Editora Massangana, 2010. 